\title{
Electric Water Heater Modelling for Direct Load Control Demand Response
}

\author{
Md Tofael Ahmed, Pedro Faria, Omid Abrishambaf, Zita Vale \\ GECAD - Research Group on Intelligent Engineering and Computing for Advanced Innovation and Development \\ Polytechnic of Porto (IPP), Porto, Portugal \\ mdtof@isep.ipp.pt, pnf@isep.ipp.pt, ombaf@isep.ipp.pt, zav@isep.ipp.pt
}

\begin{abstract}
Home Energy Management System creates the scopes to small household electrical appliances users to participate in the demand response programs. Among several load controllable electrical household appliances water heater is more suitable. Integration of water heater is considered to manage the demand response events that can contribute to smart grid technology. This paper represents a thermodynamic load model for a water heater, which is considered as to be controlled through direct load control for demand response program. The daily electricity consumption and temperature profile of the heater is also considered, the direct load control method is activated to the heater as soon as the energy consumption reaches to $1 \mathrm{~kW}$, with the effects the device is turned off for next one hour. In results, it gained a significant reduction in the electricity consumption for the users without making any discomfort as temperature does not reduce to disruption level. Real time electricity pricing is also compared which implied financial benefit to the consumers. The result exhibit that the method applied to this heater can contribute and participate in the demand response events.
\end{abstract}

Keywords-Home Energy Management System, Demand Response, Direct Load Control, Load Modelling.

\section{INTRODUCTION}

There is increase in electricity generation by renewable energy resources due to the growing need of low-carbon electricity. Demand response (DR) helps to make a balance between the load and power generation in our conventional electrical infrastructure. It gives emergency support to the grid, fill valleys, shave peak load. The vast advantages of electric water heaters (EWHs) usage makes it an appropriate candidate for the DR purpose. Electric water heater consumes a major power $(7.5 \%$ to $40 \%)$ in the residences total energy consumption [1]. The switching actions in that type of heaters are very flexible as the elements are resistors and there is no support of reactive power needed from the grid [2]. There is also no energy waste for balancing services and these heaters can be used as energy storage additionally [2]. It is very useful for the home energy management system as it has load shifting and shaving services.

The electrical household appliances are considered as the major parts of the house due to using necessity [3]. With the increase of load density in the residential sectors there is a

chance of increasing power consumption too. The consumption problem considered as one of the major problem in recent years [4]. The smart grid solutions are the best in recent years to support renewable energy potential by giving electrical grid flexibility [5,6,7]. It is possible to provide benefits to the suppliers, customers and also the grids by developing smart grids [8]. By means of using DR and energy from several renewable energy sources a balance can be made between load and power generation. For the implementation of DR in residential sectors, the houses must consist of smart intelligent technologies for example smart meters, smart sensors, smart plugs and other smart devices [9].
Load model is required for the customers to understand the overall power consumption and signals from the utility including the smart grid concept expansion and implementation of DR control strategy [10]. It is not so easy rather challenging to understand load models though several studies and uses regarding load model has already done in last years. To obtain precise load models with new techniques a brief study is necessary which can match simulated behaviours with measured real data [11]. Load modelling is very important to study the residential DR events at the distribution circuit level also to study consumer action.

The main purpose of using DR in residential system is to penetrate customers power consumption reduction activities. The pricing, DR signals are set by the prior agreements between consumer and the utility $[12,13]$. Home energy managements (HEMS) requires studying customers behaviours which can be achieved by home appliance modelling [14]. Home appliance modelling is also important to understand the control strateges of DR events. Several researchers have considered physical load models in the case of HEMS and residential DR studies. In this paper, improved modelling of electric water heater $(\mathrm{EWH})$ has developed based on the physical characteristics of the appliances. A case analysis with real data of an EWH has been studied to validate its participation in DR event with the integration of HEMS.

The rest of paper is organized as follow. Section II represents the description regarding HEMS. EWH modelling is represented in Section III. A case study in Secion IV validates the performance of proposed system, and its results are provided in Section V. Finally, the main conclusions of the paper are mentioned in Section VI.

\section{Home ENERGy MANAGEMENT SySTEM (HEMS)}

The growing electricity demand and the evolution of smart grids have conferred the advanced opportunities for the HEMS.

It is a management system for DR to improve the energy consumption and production profile from consumer demand side. The main tasks of the HEMS are to create production schedules and optimal consumption. In order to complete the

method several conditions for example load profiles, costs of energy, environmental issues and customer comfort are taken into consideration. It can reduce electricity operational cost for a certain percentage, the peak demand of the households, can minimize energy waste, and it is eco-friendly. It is an advanced type of technology that can response the altered condition without human interaction.

Home energy management is developed by the reduction of energy usage, increase in energy efficiency and building integration of renewable energy sources. The assurance of the smart grid technologies can therefore be fulfilled if it can make 
sure the greater engagement, response and assistance from the residential consumers [15]. To effectively participate in the DR programs introduction of HEMS is very important. In DR activation program, it is required to correspond with an automated program by an optimization algorithm which is known as HEMS. They have active participation and contribution regarding household DR as well.

The HEMS can contribute to all kinds of DR programs [16]. The development of HEMS and its expansion with smart metering system, monitoring of smart household, advanced computer technologies for electricity management is occurred during recent years rapidly [17]. HEMS is considered as the fundamental part in the electricity distribution system that creates the scope for residential customers to participate in the DR program. A HEMS makes a DR operation full automated which is very convenient to use by the consumer. The main operation of the HEM is to monitor and manage all the operations of the household appliances and to provide the desired output based on the required settings[18].

For smart home energy management (SHEM) the DR programs in small residences is mostly important. For successful demand-side management of smart grids smart HEMS is considered as the most fundamental system [19]. Human-machine interface in smart houses is used to monitor, control and scheduling in real-time based on the set preferences of the user. HEMS require studying customers behaviours which can be achieved by home appliance modelling. Home appliance modelling is also important to understand the control strategy of DR. Several researchers have considered physical load models in the case of HEMS and residential DR studies. The minimization of the customers cost is the main catalyst of using HEM in the household appliances. The output is obtained as the energy consumption schedule of appliances. It is controllable by solving an optimization-based HEM problem [20].

HEMS is a part and parcel of smart grid energy technology It is a combination of the hardware and software interconnected systems that can manage the household energy consumptions [21]. The HEMs and its functions can be summarized as: A managing system which is responsible to work for the management of energy consumption, production, grid integration, modification by providing the information to the

consumers.

It does not require any human interaction to run the overall system.

It makes the option to control the household appliances to be modified by the third parties or the consumer themselves by using smart devices and technologies.

The design and architecture for HEMS varies according the requirements and desired outputs. In last years, several HEMS for DR purpose have been developed by using appropriate hardware and software. The overall architecture of the proposed model in HEMS is illustrated in the Fig. 1. The focus of the model is given to control the electrical water heater during DR events. For this purpose, a HEMS is employed in the model to control and manage the electrical water heater during DR events.

As you can see in the Fig.1, the HEMS have communication with the DR managing entity, which can be considered as an aggregator. The entity defines the DR events, and transmits the related information to the HEMS, therefore, HEMS control the related devices based on the amount of reduction. In this paper, it is considered Direct Load Control (DLC) for the DR participation of the residential consumer [21].

In the meanwhile, smart meter utilized in this model measures the real-time electricity consumption of the electrical water heater and transmits the information to the HEMS to be transmitted to DR managing entity.

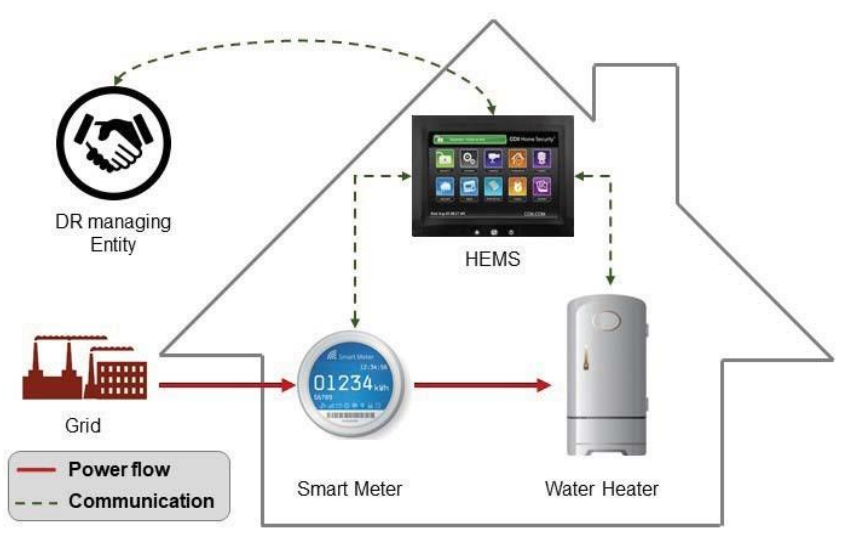

Fig. 1. A smart household representation with electrical water heater.

In order to understand the DR event for electrical water heater (EWH) in a small house it is important to study and analyse the EWH modelling.

\section{EWH MODELLING}

The idea behind EWH load modelling is to establish a connection between its parameters and the total power consumption. The parameters of an EWH consists of physical characteristics, water temperature, ambient temperature and water usage. The on/off status of the device is obtained by including the parameters in a simulated model. In some cases, it is very challenging to obtain the desired parameters from EWH [22]. A single element electric water heater for residential household is considered here. The benefit of using single element EWH is that it can classify the thermodynamic model by using heater power measurements only, it is easy to

clarify and simulate different loads. Such thermodynamic model can be stated as[23]:

$$
\begin{gathered}
\dot{T}(t)=\frac{1}{C}\left[Q(t)-G\left(T(t)-T_{\text {out }}\right)-\rho c_{p} W_{D}(t)\left(T(t)-T_{\text {in }}\right)\right] \\
P(t)=\left[\begin{array}{ll}
P_{0} & T(t) \leq T_{\text {low }} \\
0 & T(t) \geq T_{\text {high }} \\
P(t-\delta t) & \text { otherwise }
\end{array}\right] \\
Q(t)=P(t) \times u(t)
\end{gathered}
$$

(3) where $\mathrm{C}$ is thermal capacity, $\mathrm{Qt}$ is heater power, $\mathrm{G}$ is thermal resistance, $\mathrm{T}_{\text {out }}$ is the ambient temperature, is water density, $c_{p}$ is specific heat, $W_{D}$ is water demand, $T_{i n}$ is inlet water temperature.

For DR implementation, there are several EWHs models are existing based on their functions. In [5], the considered 
simulation model of outlet water temperature for DR purpose is:

$$
\begin{aligned}
& T_{\text {outlet }, 1}=\left(\frac{T_{\text {outlet }}\left(V_{\tan k}-V \times d t\right)+T_{\text {inlet }} \times F_{\text {water }} \times d t}{V_{\tan k}}\right)+ \\
& \left(\frac{d t}{60} \times\left(\frac{P_{\text {rated }}}{V_{\tan k}}\left(\frac{3412 B T U}{k w h}-\frac{A_{\tan k} \times\left(T_{\text {outlet }}-T_{\text {amb }}\right)}{R_{\tan k}}\right)\right)\right)
\end{aligned}
$$

where $F_{w a t e r}$ is the hot water flow rate $\left(\mathrm{m}^{3} / \mathrm{s}\right), T_{\text {inlet }}$ is the inlet water temperature $\left({ }^{\circ} \mathrm{C}\right), \mathrm{V}_{\text {tank }}$ is the tank volume $\left(\mathrm{m}^{3}\right), \mathrm{A}_{\text {tank }}$ is the tank surface area $\left(\mathrm{m}^{2}\right), \mathrm{R}_{\text {tank }}$ is the tank heat resistance $\left({ }^{\circ} \mathrm{c} . \mathrm{m}^{3} \cdot \mathrm{h} / \mathrm{btu}\right), \mathrm{T}_{\mathrm{amb}}$ is the ambient temperature, $\mathrm{dt}$ is the time slot duration $(t)$. The status of the device indicates whether it can be operated for DR implementation or not. Mathematical expression for this operation is [5]:

$$
m_{\text {heater }}=\left[\begin{array}{ll}
1 & T_{\text {heater }, t}<T_{\text {set }}-\Delta T \\
0 & T_{\text {heater }, t}<T_{\text {set }}+\Delta T \\
m_{\text {heater }, t-1} & T_{\text {set }}-\Delta T \leq T_{\text {heater }, t} \leq T_{\text {set }}+\Delta T
\end{array}\right] \times S n_{t}
$$

Here, $\mathrm{T}$ is the dead band temperature $\left( \pm 2^{\circ} \mathrm{C}\right)$ and $\mathrm{Sn}_{t}$ is the DR signal. The DR signal controls the electric power demand of the water heater. At the time of DR period, the consumer can change the originated signal from the revised thermostat set point.

The comprehensive one-node and two-node model for the heat transfer process in an EWH is discussed in [24]. It is a thermal model which is used to control the heating device's on/off status. The one-node model of an EWH are considered for our case. First order differential equation is used to model the heat transfer processes. The model can be stated as [25]:

$$
Q_{\text {elec }}-\dot{m} C_{p}\left(T_{w}-T_{\text {inlet }}\right)+U A_{w h}\left(T_{a m b}-T_{w}\right)=C_{w} \frac{d T_{w}}{d t}
$$

where, Qelec is the resistor heating capacity (BTU/hour), $m$ is the water flow rate (lb/hour), $C_{p}$ is the thermal capacitance

$\left(\mathrm{BTU} /\left(\mathrm{lb} .{ }^{\circ} \mathrm{F}\right)\right), \mathrm{T}_{\mathrm{w}}$ is the water temperature $\left({ }^{\circ} \mathrm{F}\right), \mathrm{T}_{\text {inlet }}$ is the inlet water temperature $\left({ }^{\circ} \mathrm{F}\right), \mathrm{UA}_{\mathrm{wh}}$ is thermal conductance

(BTU/ $/{ }^{\circ} /$ hour), $\mathrm{T}_{\mathrm{amb}}$ is the room temperature $\left({ }^{\circ} \mathrm{F}\right), \mathrm{C}_{\mathrm{w}}$ is thermal capacitance $\left(\mathrm{BTU} /{ }^{\circ} \mathrm{F}\right)$. The switching action of the heater can be controlled by measuring the actual temperature of any given time. It can be calculated by using this model.

\section{CASE STUdy}

This paper represents a case study considering an electric water heater's load control, temperature profile, overall consumption and price schedule. The case is studied and analysed for the heater's electricity consumption and its output behaviour. The consumption and output data are obtained and then considered for the participation in the demand response events. Additionally, the electricity pricing method is also considered and calculated to obtain the financial benefit.
The considered EWH is a single sensor heater from our office building of Research Group on Intelligent Engineering and Computing for Advanced Innovation and Development (GECAD). This is the only heater existing in the building which is used by several people. A temperature sensor is set just outside the heater that can measure the water outlet temperature in real time. A set temperature is also considered to maintain the temperature level inside the EWH.

The purpose of the analysis is to model the heater for DR events and to consider whether it can participate in DR events, if not how it can be modified or developed to make sure that it can participate in DR programs. It is also considered to confirm that it does not interrupt the comfort level of the consumers in the building.

Fig. 2 shows the overall consumption and exit water temperature with respect to the time in hour. It also shows temperature fluctuations very clearly. The data are taken for 24 hours period from a morning to another morning with 5 minutes of interval.

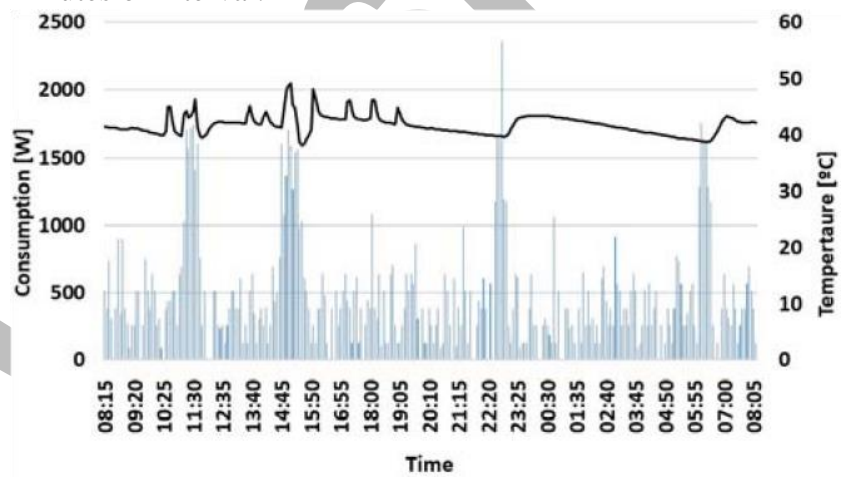

Fig. 2. Overall consumption for one day period.

The specific date of collecting data from the database is $17^{\text {th }}$ January 8.15 am to $18^{\text {th }}$ January 8.10 am of the EWH of GECAD building. Additionally, the market price is also taken into consideration for the purpose of financial benefit calculation. Initial market pricing data are taken form Portuguese sector of Iberian Electricity Market (MIBEL) (www.omie.es).

The Fig. 2 also illustrates the electricity consumption and fluctuations for the EWH. From there it is seen that there is higher consumption in few certain hours for a certain period which has impact on temperature rising. It can be clearly seen from the figure that with the increase in consumption there is increase in temperature of the heater. It also exhibits the overall

\section{consumption profile of the EWH.}

Fig. 3 represents hourly real time pricing of the considered days (for 24 hours) in Portugal. The price is taken form the electricity market then it is considered to calculate the approximate value for the consumers. As it is seen from the figure that the prices of the electricity vary with the time so the costs from demand side also vary according to the consumption hour.

The objective is to know the amount of energy consumption it can reduce of this EWH by using DR and smart controlling system as it is beneficial for the end users. Also, it is analysed how the consumers can be financially benefitted by reducing the consumption after DR integration. It can contribute to the national economy as well by reducing the consumption during peak hours. The methodology is to turn off the EWH while the consumption reaches to $1000 \mathrm{~W}$ by controlling the load directly for next one hour. 


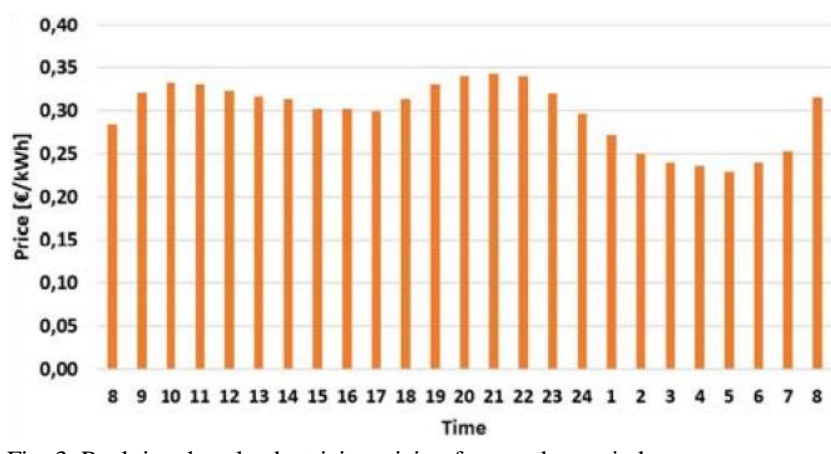

Fig. 3. Real time hourly electricity pricing for one day period.

Fig. 4 illustrates the restricted energy consumption for electrical water heater. It can be seen in the Fig. 4 that there is a control barrier in the consumption level of $1000 \mathrm{~W}$. The red line indicates the consumption control level of the EWH.

The result and the impacts are shown in the next part.

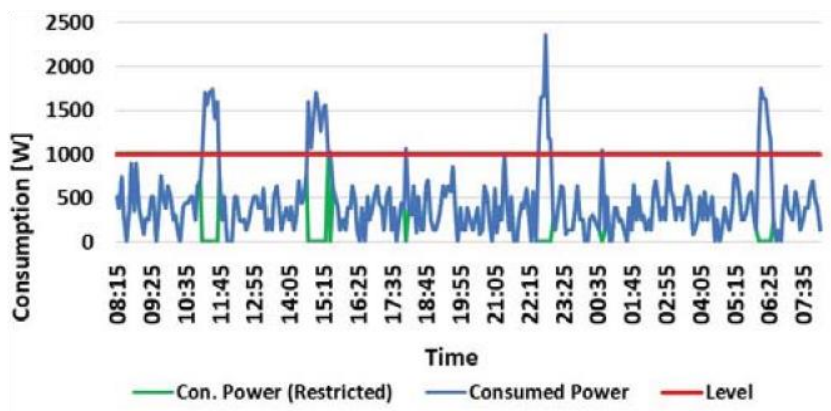

Fig. 5. EWH load controlled energy consumption.

Fig. 6 shows the temperature difference between two stages of the EWH. The first temperature profile here is normal daily temperature and the second temperature profile is after controlling the load. It can be seen very clearly the differences between these two temperatures profile in the figure. It is found that the difference is so low that it does not make any discomfort level for the users. By using the proposed load controlled method, it is assured that the selected EHW does not affect the consumers consumption behaviour and user satisfaction.

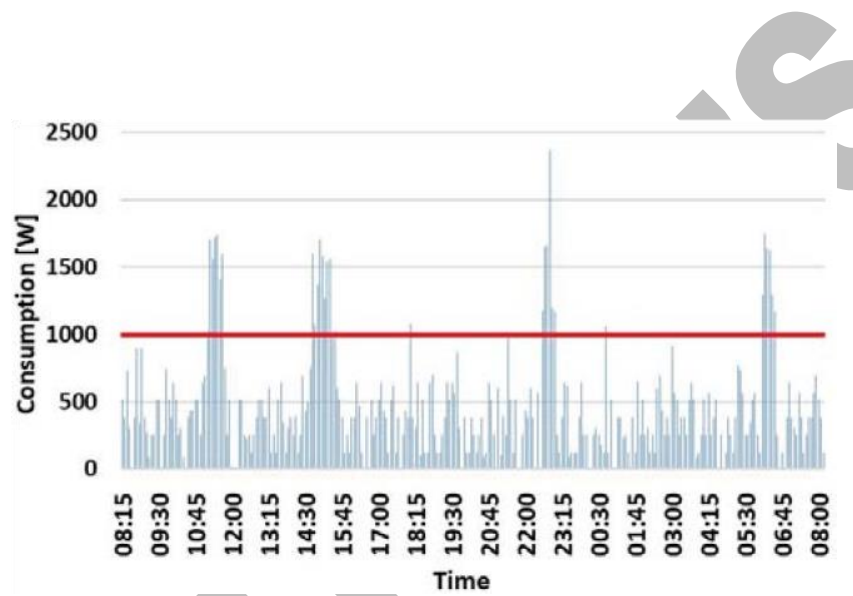

Fig. 4. EWH restricted energy consumption.

\section{RESUlt ANALYSIS}

The impact on the energy consumption after using the EWH by proposed method is shown in the Fig. 5. As it can be seen from there that when the consumption reaches to $1000 \mathrm{~W}$ then it turned off immediately and continues to the next one hour. The control method is considered here to control the energy consumption by using load control. The output is the energy usage reduction for that period which is beneficiary for the consumers. From the result, it is found that the energy consumption is reduced to almost half in that day after using the load control method.

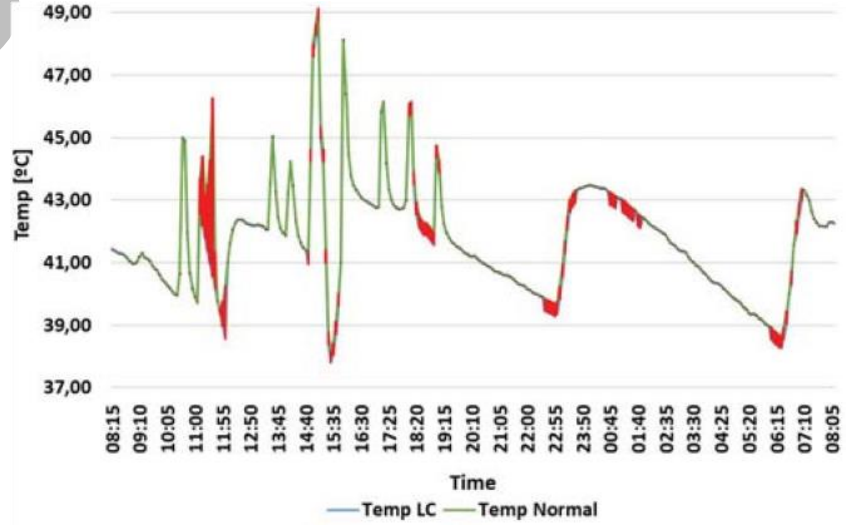

Fig. 6. Temperature difference between two stages.

The price reduction per unit electricity after using load control is shown in the Fig. 7. From there it can be seen that the price is significantly reduced based on the hourly consumption of the EWH at the experimented day. The line in blue indicates the price for users regular consumption and the other line shows the price for users consumption after controlling the load. So, it is another benefit for the both consumer and the state. 


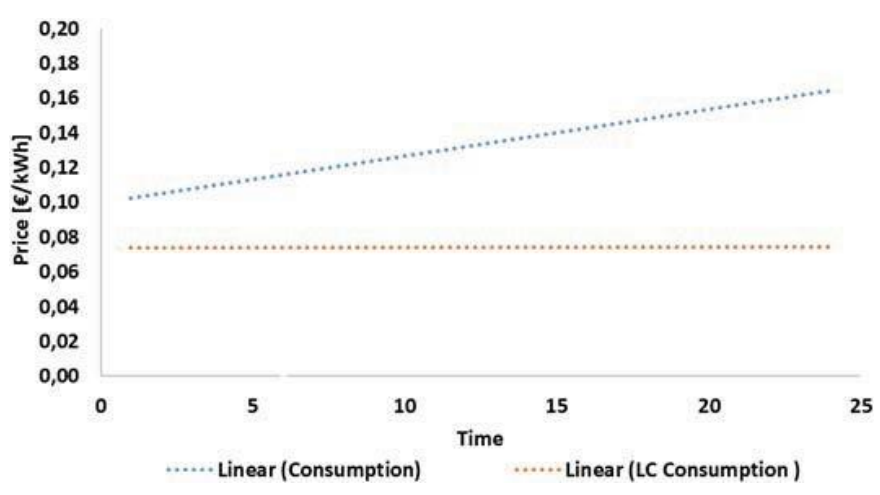

Fig. 7. The price difference between two stages.

After having a brief analysis, it is considered that our experimented electric water heater can participate in Direct Load Control (DLC) program of DR events. As it is found that if the heater turns off for a certain period it does not affect the consumers. The direct load control is mainly controlled by the aggregators for a certain period when they need it.

Actually, they can use the DLC program during peak hours to reduce the consumption. If it can confirm the participation of our device in the DR event, then all can be benefitted financially without having any discomfort. Alternatively, it can control the load by using smart controlling in the given method which is also beneficial for the consumer.

\section{CONCLUSIONS}

In this paper, residential home appliances such as electrical water heater's model with optimization-based home energy management system is developed for the demand response participation purpose. Both operational and physical characteristics are considered to achieve demand response strategies. Integration of electric water heater in home energy management system is briefly discussed here. It enables and make beneficiary for small appliances to participate in the DR events.

The experimental real data of an electric water heater is considered for the analysis by using direct load control method. After the analysis it is found that the electric water heater can be considered for the direct load control during this it can maintain the consumers comfort level by suiting their preferences. The temperature does not change significantly while using the direct load control method for demand response to the heater. The direct load control method reduces the consumers energy consumption which is financially profitable. By using proposed method, it can be concluded that the indicated water heater is able to participate in the demand response event.

\section{ACKNOWLEDGEMENTS}

The present work was done and funded in the scope of the following projects: H2020 DREAM-GO Project (Marie Sklodowska-Curie grant agreement No 641794); SIMOCE (ANI|P2020 17690); and UID/EEA/00760/2013 funded by FEDER Funds through COMPETE program and by National Funds through FCT.

\section{REFERENCES}

[1] B. Lin, S. Li and Y. Xiao, "Optimal and learning-based demand response mechanism for electric water heater system," Energies , 10(11), 1722, October 2017.
[2] Z. Xu, R. Diao, S. Lu, J. Lian, and Y. Zhang, "Modeling of Electric Water Heaters for Demand Response: A Baseline PDE Model," IEEE Transactions on Smart Grid, vol. 5(5), pp. 2203-2210 September 2014.

[3] F. Fernandes, H. Morais, Z. Vale, C. Ramos, "Dynamic load management in a smart home to participate in demand response events," Energy Build., 82, pp. 592-606, October 2014.

[4] P. Faria, J. Spínola and Z. Vale, "Reschedule of Distributed Energy Resources by an Aggregator for Market Participation," Energies, vol. 11(16), pp. 713, March 2018.

[5] M. S. Ahmed, A. Mohamed, R. Z. Homod, H. Shareef, and K. Khalid, "Modeling of Electric Water Heater and Air Conditioner for Residential Demand Response Strategy," International Journal of Applied Engineering Research, vol 11(16), pp. 9037-4562, January 2016.

[6] S. Rahman, "Smart grid expectations [In My View]," Power and Energy Magazine, IEEE, vol. 7(5):88, pp. 84-85, October 2009.

[7] T.Pinto, Z. Vale, I. Praça, 1. Gomes, P. Faria, "Mulit-agent Electricty Markets and Smart Grids Simulation with Connection to Real Physical Resources," in Electricity Markets with Increasing Levels of Renewable Generation: Structure, Operation, Agent-based Simulation, and Emerging Designs, Springer International Publishing AG, February 2018.

[8] T. J. Lui, W. Stirling, and H. O. Marcy, "Get Smart," Power and Energy Magazine, IEEE, vol. 8(3), pp. 66-78, April 2010.

[9] N. Gudi, L. Wang, and V. Devabhaktuni, "A demand side management based simulation platform incorporating heuristic optimization for management of household appliances," Int. J. of Electrical Power \& Energy Systems, vol. 43(1), pp. 185-193, April 2011.

[10] R. Z. Homod, K. S. M. Sahari, H. A. Almurib, and F. H. Nagi, "Double cooling coil model for non-linear HVAC system using RLF method," Energy and buildings, vol. 43(9), pp. 2043-2054, September 2011.

[11] P. Siano, "Demand response and smart grids - A survey," Renewable and Sustainable Energy Reviews, vol. 30, pp. 461-478, February 2014.

[12] H. T. Haider, O. H. See, and W. Elmenreich, "A review of residential demand response of smart grid," Renewable and Sustainable Energy Reviews, vol. 59, pp. 166-178, June 2016.

[13] M. Beaudin and H. Zareipour, "Home energy management systems: a review of modelling and complexity," Renewable and Sustainable Energy Reviews, vol. 45, pp. 318-335, May 2015.

[14] O. Abrishambaf, M. Ghazvini, L. Gomes, P. Faria, Z. Vale and J. Corchado, "Application of a Home Energy Management System for Incentive-Based Demand Response Program Implementation,”2016 27th International Workshop on Database and Expert Systems Applications (DEXA), pp. 153-157, 2016.

[15] M.S. Thomas, P. Bansal and P. Taneja, "Smart home energy management by Demand Response controller design," 6th India Int. Con. on Power Electronics (IICPE), pp. 1-6 December 2014.

[16] M.A.F. Ghazvini, J. Soares, O. Abrishambaf, R. Castro and Z. Vale, "Demand response implementation in smart households", Energy and Buildings, vol. 143, pp. 129-148, March 2017.

[17] M. Hu, and F. Xiao, "Investigation of the Demand Response Potentials of Residential Air Conditioners Using Grey-box Room Thermal Model," Energy Procedia., vol.105, pp. 2759-2765, May 2017.

[18] M. Pipattanasomporn, M. Kuzlu and S. Rahman, "An algorithm for intelligent home energy management and demand response analysis," IEEE Trans. Smart Grid, vol. 3(4), pp. 2166-2173, 2012.

[19] B. Zhou, W. Li, K.W. Chan, Y. Cao, Y. Kuang, X. Liu, and X. Wang, "Smart home energy management systems: concept, configurations, and scheduling strategies", Renewable and Sustainable Energy Reviews, vol. 61, pp. 30-40, August 2016.

[20] M. Rastegar, M. Fotuhi-Firuzabad, and H. Zareipour, "Home energy management incorporating operational priority of appliances,” Int. J. of Electr. Power \& Energy Systems, vol. 74, pp. 286-292.

[21] P. Faria, Z. Vale, "Demand response in electrical energy supply: An optimal real time pricing approach", Energy, vol. 36, no. 8, pp. 53745384 , Aug. 2011.

[22] B. Karlin, R. Ford, A. Sanguinetti, C. Squiers, J. Gannon, M. Rajukumar, and K.A. Donnelly, "Characterization and Potential of Home Energy Management (HEM) Technology," Pacific Gas and Electric, San Francisco, CA (2015). 
[23] Mostafa S. Zolpirani, Design of a Direct Load Control Program for Residential Electric Water Heaters. PhD Thesis, Dept. of Electrical and Computer Engineering, University of New Brunswick, July 2016.
[24] X.S. Jiang, Z.X. Jing, Y.Z. Li, Q.H. Wu, and W.H. Tang, "Modelling and operation optimization of an integrated energy based direct district waterheating system" Energy, vol. 64, pp. 375-388, January 2014.

[25] R. Diao, S. Lu, M. A. Elizondo, E. T. Mayhorn, Y. Zhang, and N. A. Samaan, "Electric water heater modeling and its control strategies for demand response", IEEE Power and Energy Society General Meeting, July 2012. 